\title{
Intelligent Energy Management System for a Smart Home Integrated with Renewable Energy Resources
}

\author{
Arjun Baliyan $\mathbb{D},{ }^{1}$ Isaka J. Mwakitalima $\mathbb{D}^{2},{ }^{2}$ Majid Jamil $\mathbb{D},{ }^{1}$ and M. Rizwan $\mathbb{D}^{3}$ \\ ${ }^{1}$ Department of Electrical Engineering, Jamia Millia Islamia, New Delhi 110025, India \\ ${ }^{2}$ Department of Electrical and Power Engineering, Mbeya University of Science and Technology, P.O. Box 131, Mbeya, Tanzania \\ ${ }^{3}$ Department of Electrical Engineering, Delhi Technological University, Delhi 110042, India
}

Correspondence should be addressed to Arjun Baliyan; arjunresearch16@gmail.com

Received 24 October 2021; Revised 21 December 2021; Accepted 19 January 2022; Published 8 February 2022

Academic Editor: Yaxuan Xiong

Copyright (C) 2022 Arjun Baliyan et al. This is an open access article distributed under the Creative Commons Attribution License, which permits unrestricted use, distribution, and reproduction in any medium, provided the original work is properly cited.

In this paper, an intelligent energy management system for the smart home that combines the solar energy as well as the energy from the battery storage devices has been proposed to reduce the dependency on the power grid and make the system to be more economical. The proposed system manages the energy requirement of the smart home by properly rescheduling and arranging the power flow between the energy storage devices, grid power, and the photovoltaics. The power grid can absorb the excess power from the designed system whenever the load requirement is low, and on the other hand, it can supply the power to the load in case of peak demand. Therefore, in the designed system, a user has the flexibility to sell the extra power for the purpose of revenue. A thorough simulation of the system has been carried out, and the results obtained show the effectiveness of the approach in terms of energy management between the different sources.

\section{Introduction}

Renewable energy resources (RER) are getting popularity nowadays since they are environmentally friendly and available in abundance. Also, due to the rapid decline in the conventional energy resources, the renewable sources are the best alternative to replace them. A home energy management (HEM) system is basically a system that has been designed with the help of renewable energy resources with an aim to reduce the overall energy consumption. This type of configuration is usually done in order to reduce the electricity bill and manage the peak load demand. Apart from it, the research on converting the power grid into smart grid by combining the already existing grid with the renewable energy resources will further reduce the dependency on the conventional energy resources [1]. In the recent years, research topics focus on home energy management integrated with storage devices and the photovoltaics [2-9]. In [2-5], the authors have considered energy cost minimization as an optimization problem based on the unpredictable behaviour of the output from the renewable energy resources. In [6-8], demand response (DR) programs have been explained for the priority wise rescheduling of the load based on the prediction of renewable energy (RE) output. In [9], the dependence on the battery and its characteristics have been explained and how they can be useful in-home energy management. In $[10,11]$, the photovoltaic integrated with the home energy management is discussed in detail. Although a lot of discussion on the integration of energy storage units and photovoltaics with the HEM have been explained in the literature [12-14], but still there are certain issues that need to be resolved. For example, how the battery can play an important role in case the power from the solar panel is not sufficient to fed the load and how much benefit the renewable sources of energy can provide in case of peak load demand. This paper resolves one of the such issues by proposing an integration of storage devices and photovoltaics with the HEM that provides surplus power to the grid 


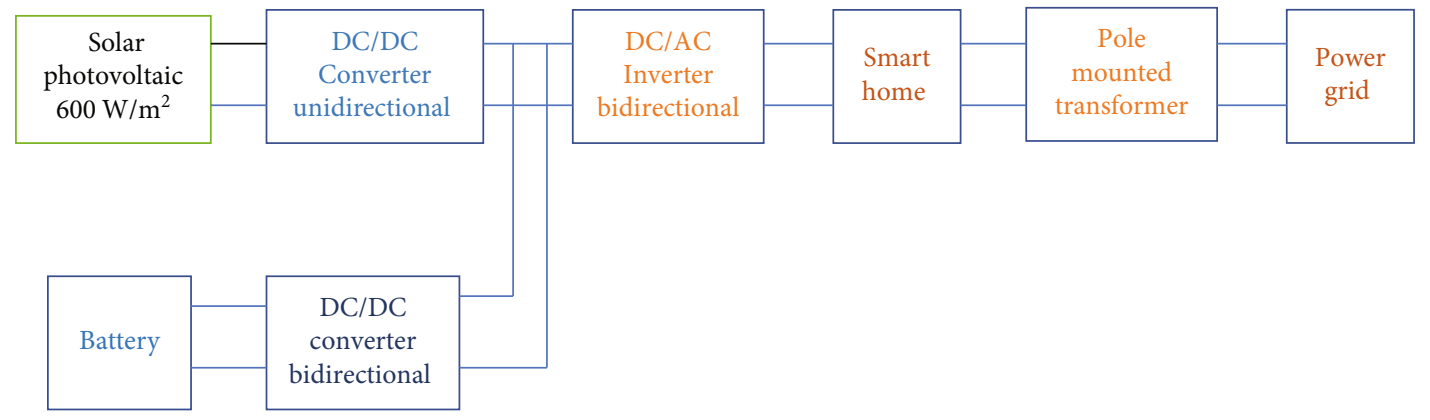

Figure 1: Block diagram of the system.

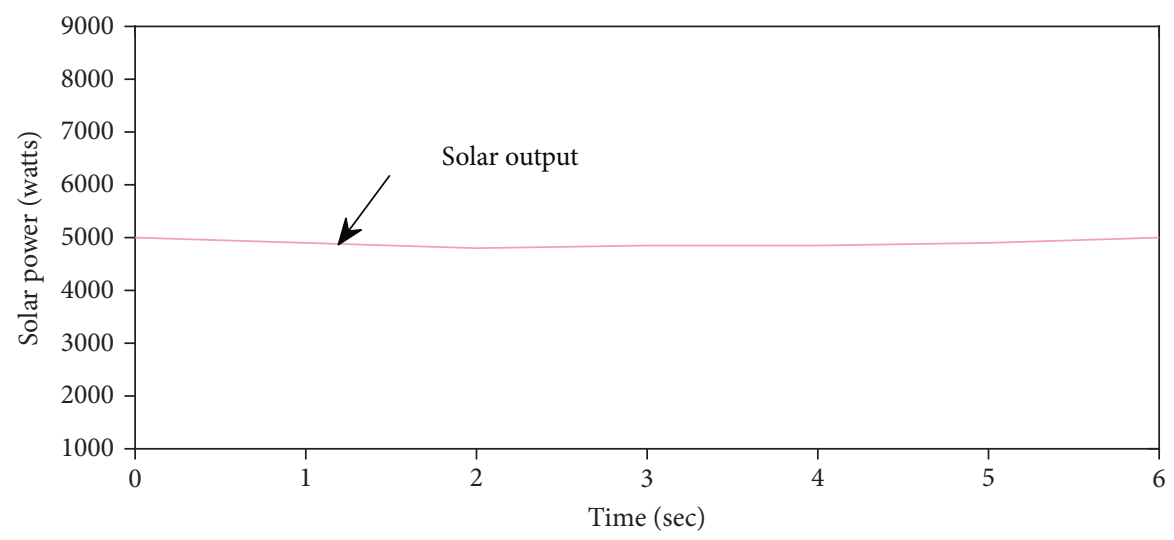

FIGURE 2: Solar panel output.

TABLE 1: Battery specifications.

\begin{tabular}{lcc}
\hline S. no. & Battery parameters & Values \\
\hline$(1)$ & Nominal voltage & $24 \mathrm{~V}$ \\
$(2)$ & Ampere-hour & $40 \mathrm{Ah}$ \\
$(3)$ & State of charge (SOC) & $80 \%$ \\
$(4)$ & Fully charged voltage & $232.7 \mathrm{~V}$ \\
\hline
\end{tabular}

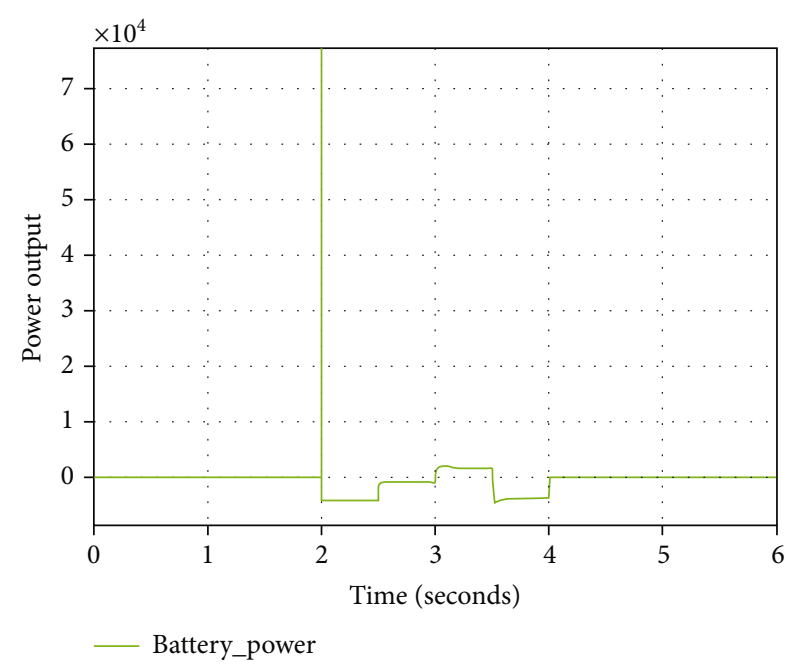

Figure 3: Battery characteristics. as well as absorb power in case of deficiency. Hence, a perfect balance is maintained to make the system more reliable and economical.

The paper is arranged as per the following sections: Section 2 describes the proposed system, Section 3 explains the obtained simulation results, and Section 4 finally concludes the paper.

\section{Simulation Components of Proposed System}

This method explains how the existing HEM model can be integrated with the renewable energy resources and the battery storage devices. The block diagram of the above proposed system is given in Figure 1.

Photovoltaics and battery storage devices are working as a complementary power source for a smart home. The rating of photovoltaic system is $5 \mathrm{~kW}$ and is described by the current voltage look up table. In order to track the maximum power point, MPPT control algorithm has been used which extracts maximum power under variable system conditions.

2.1. Photovoltaic (PV) System. In this system, PV and the storage device models are developed in order to make the HEM system to operate in integration with the renewable energy resources. To track the maximum power from the solar panel, MPPT technique [15] has been applied which manages the operating point of the array in such a way that 


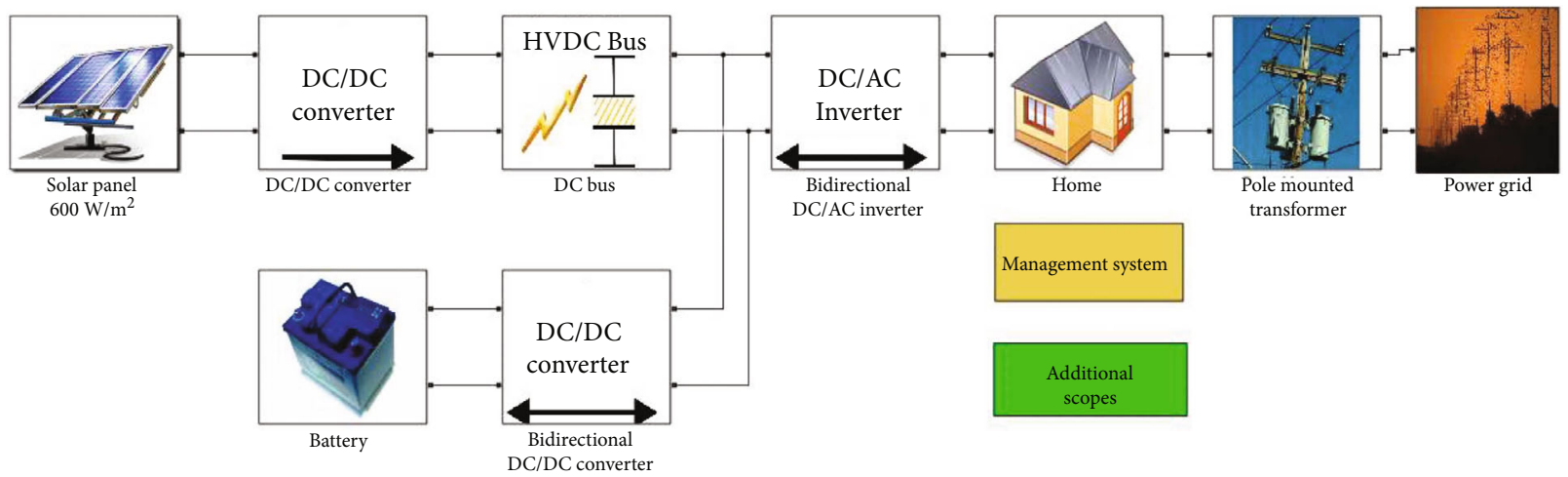

FIgURE 4: Simulation of the proposed system.
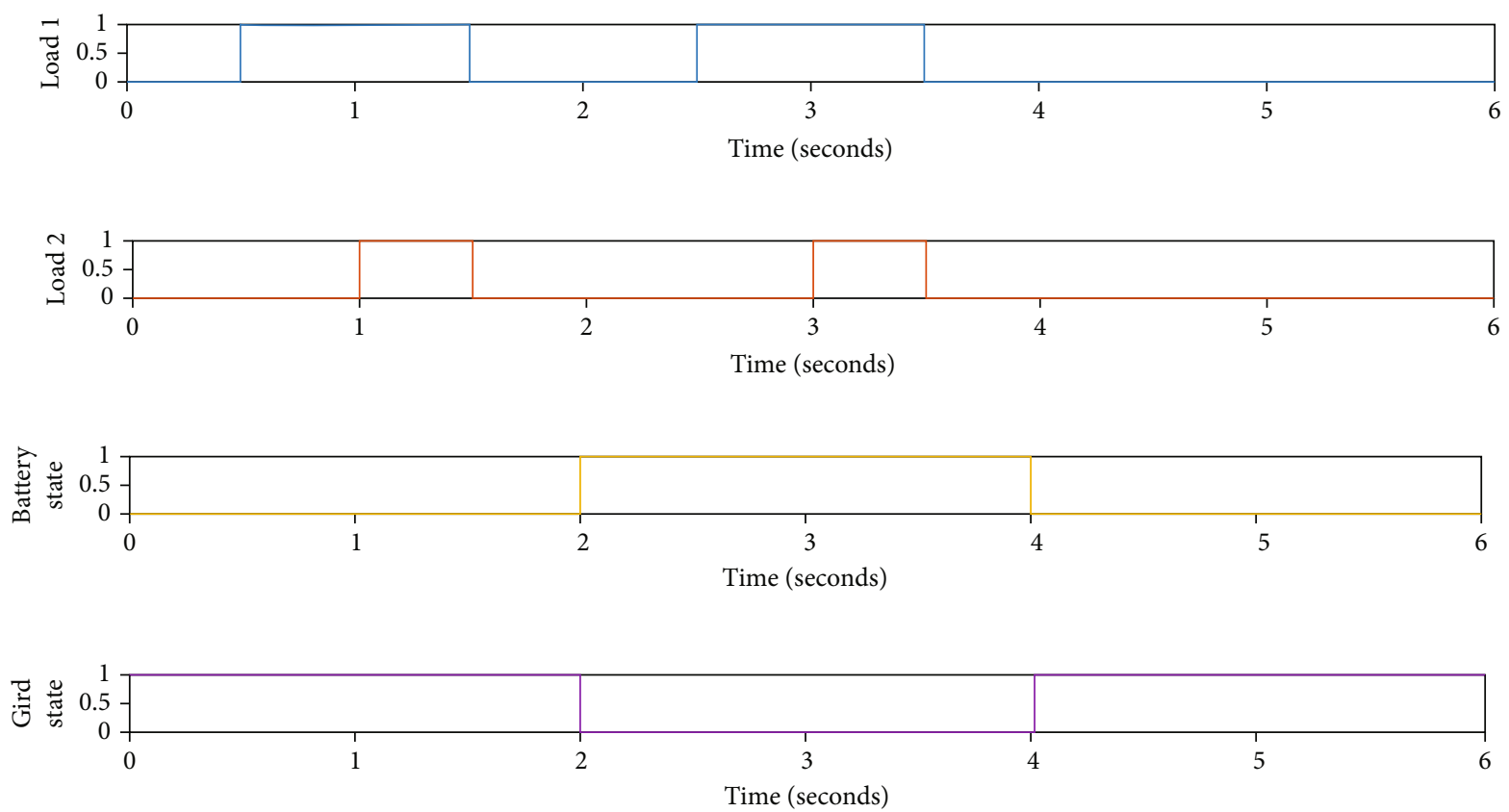

FIGURE 5: Switching characteristics of loads, battery, and power grid.

it always obtains the maximum power in the different varying conditions.

For photovoltaic system, the energy output or the energy delivered is given by the following

$$
E_{B}=\mathrm{Q} \rho_{A} C_{g t} t\left(1-\delta_{p}\right)\left(1-\delta_{c}\right)
$$

where $Q$ is the array area in $\mathrm{m}^{2}, \rho_{A}$ is the average efficiency of an array (\%), $C_{g t}$ is the global radiation, $T$ is the time period in secs, $\delta_{p}$ is the PV panel losses (\%), and $\delta_{c}$ is the power conditioning losses (\%). follows:

And the power absorbed by the grid can be defined as

$$
E_{\text {grid }}=E_{B} * \beta_{\text {inv }} * \beta_{\mathrm{abs}}
$$

where $E_{B}$ is the energy by PV panel, $\beta_{\text {inv }}$ is the inverter efficiency (\%), and $\beta_{\mathrm{abs}}$ is the PV panel energy absorption (\%).
Figure 2 shows the output from solar panel which is around $5 \mathrm{~kW}$.

2.2. Battery Characteristics. A $200 \mathrm{~V}$ and $40 \mathrm{Ah}$ lithium-ion battery is used as a storage device to provide the power in case of peak load demand. The battery specifications are mentioned in Table 1 . The battery is charged and discharged with the help of bidirectional converter that takes power from the solar panel while charging and fed the load when solar panel alone is not enough to feed the total load demand. The battery model that has been used in the paper is explained in [16]. In the proposed system, total loads of $3 \mathrm{~kW}$ each are taken, and it was observed that in case when both the loads are ON, the solar panel was not sufficient to provide power, since the total capacity of solar photovoltaic is $5 \mathrm{~kW}$.

The battery output power (W) is shown in Figure 3. It is clear from the figure that from time $t=0$ to $t=2 \mathrm{secs}$ and $t$ $=4 \sec$ to $t=6$ secs the battery is not functioning so the extra power has to be taken from grid for that time instant. 


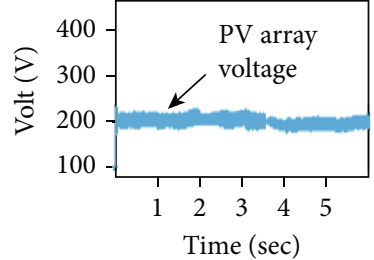

(a)

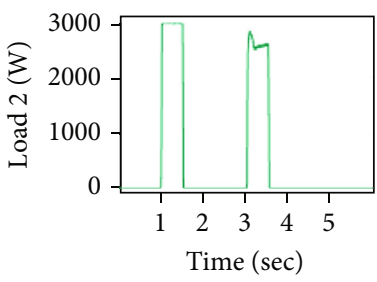

(c)

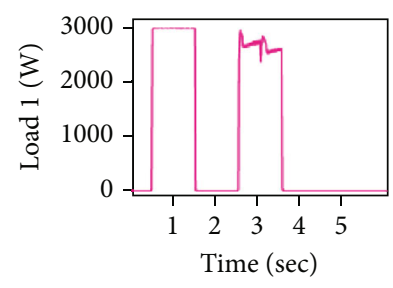

(e)

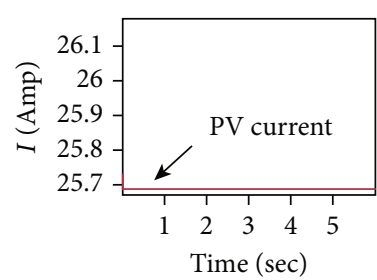

(b)

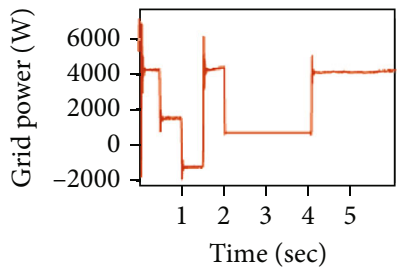

(d)

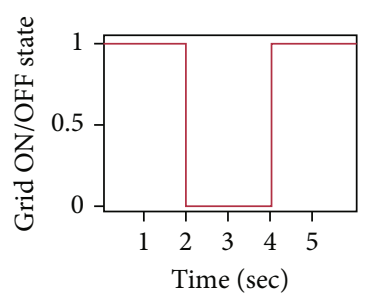

(f)

Figure 6: Load, grid, and solar photovoltaic characteristics.

\section{Simulation Results}

Initially, the battery was not connected to the system, and the loads were also disconnected, so therefore, the total solar power was transferred to the grid. The power generated by the panel was almost constant at $5 \mathrm{~kW}$, and it was obtained by MPPT control algorithm.

Case 1. One of the two loads of $3 \mathrm{~kW}$ was turned on, and it was observed that it was consuming more than half of the power produced by the solar panel, and therefore, the excess power is again transferred to the grid.

Case 2. Both the loads are turned on, and the total power demand reaches to $6 \mathrm{~kW}$, so therefore, the solar panel was not sufficient, and hence, the power demand was met by the grid.

Case 3. Now the loads are again disconnected, and the battery is connected which ensures that the total power as the combination of solar energy and storage devices is sufficient to meet the load demand when both the loads are again connected to the system in the same fashion as they were connected.

Figure 4 shows the simulation of the proposed system with renewable sources integrated with the power grid.

From Figure 5, it is clear that initially out of the two loads only one was switched at instant $t=0.5 \mathrm{sec}$ and at $t$ $=1$ secs; both the loads were on, and therefore, the grid has to supply the extra power to meet the load demand. It is also clearly visible that between the time instant $t=2$ secs to $t=4$ secs, the battery was delivering the power, and hence, the power delivered by the grid was zero. Figure 6 depicts the photovoltaic, grid power, and the load characteristics.

It can be seen from the figure that at time instant $t=1$ $\mathrm{sec}$, the total load demand hits $6 \mathrm{~kW}$ as clear from Figures 6(c) and 6(e) since the total load adds up at that time instant, but before that, only load 1 was active, and therefore, the grid that was absorbing the surplus power before $t=1$ $\mathrm{sec}$ has to now deliver the power that can be clearly visible from Figure 6(f). But again, at $t=2 \mathrm{sec}$, both the loads are in OFF state, and the battery is now in the on state, so therefore, the power will now be delivered to the grid, and the grid remains in off state. Also, Figure 6(d) shows the continuous power variation that indicates the power absorbed as well as power delivered by the grid for the entire time duration which depends on the changing load conditions. Similarly, Figures 6(a) and 6(b) give the insight of the photovoltaic (PV) voltage and current that is continuously varying according to the solar insolation. Figure 7 depicts the grid power components, solar power that remains almost constant throughout the time period, and load demand.

In the above figure, power delivered from the different renewable energy sources as well as the power absorbed by the load configuration is shown to have a better clarity of the proposed system and how it is able to manage the changing load demand with proper switching between the RER and grid power. In continuation of the above power flow diagram, Figure 7 (a) shows the power taken by the grid as well as power supplied in case of changing load conditions 


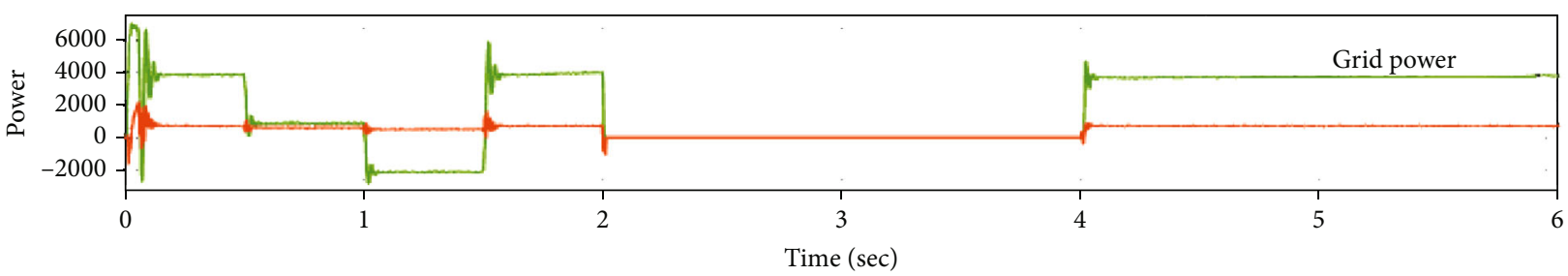

(a)

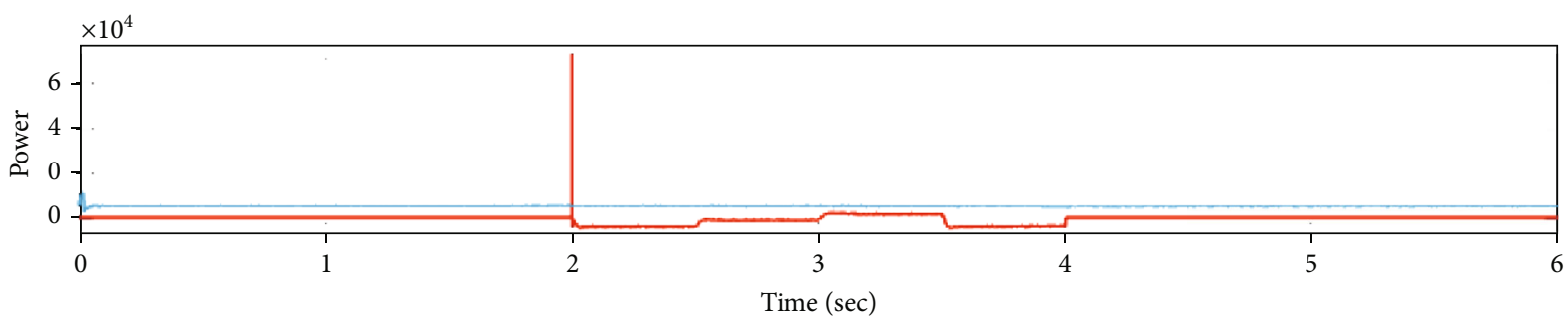

_ Battery_power

- Solar power

(b)

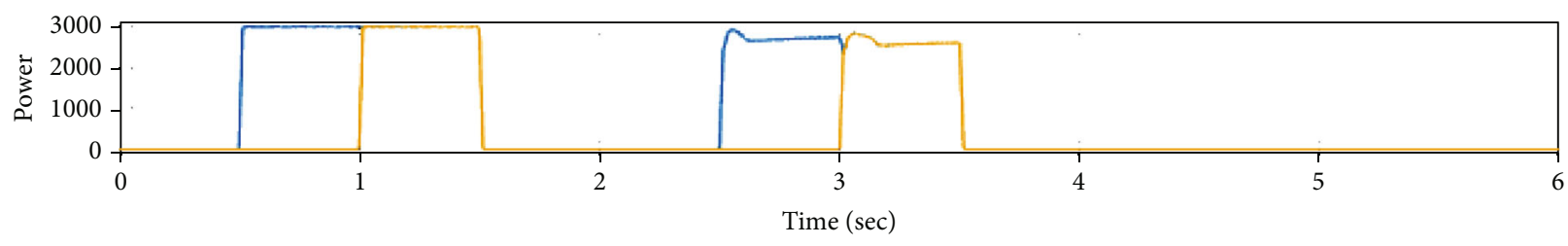

_ Load1_power[W][1]

_ Load2_power[W][1]

(c)

Figure 7: Power flow diagram.

TABLE 2: System parameters.

\begin{tabular}{lcc}
\hline S. no & Parameters & Values \\
\hline$(1)$ & Solar panel & $5 \mathrm{~kW}$ \\
$(2)$ & System loads (load 1 and load 2) & $6 \mathrm{~kW}$ \\
$(3)$ & Power grid (phase to phase voltage) & $66 \mathrm{kV}$ \\
$(4)$ & Switching frequency & $10 \mathrm{kHz}$ \\
$(5)$ & Reference voltage $\left(V_{d c}\right)$ & $370 \mathrm{~V}$ \\
$(6)$ & Inverter controller gain parameters & $K_{P 1}=0.01, K_{I 1}=25$ \\
& Tuned with PSO technique & $K_{P 2}=2.5, K_{I 2}=2.5$ \\
\hline
\end{tabular}

and the power availability conditions. Figure $7(\mathrm{~b})$ shows the variation in battery power and the solar power needed to feed the load in case of excess load demand. Similarly, Figure $7(\mathrm{c})$ illustrates the switching load pattern which clearly shows the maximum and minimum load demand in the entire time duration. The different system parameters and their values are given in Table 2.

\section{Conclusion}

This paper presents an idea of load management in case of base and peak load demand by integrating the supply with the renewable energy resources. It consists of various energy producing sources that is solar and battery storage devices as well as different energy consuming devices, called loads. Here, the switching between the different energy sources is done for energy management, and the results are shown in MATLAB. It is clear from the above results that the dependency on the grid is minimized, and even the consumer can now provide surplus power to the grid which will ultimately increase the overall revenue. The simulation shows how the HEM integrated with renewable sources is useful for residential load management, and further studies could be done in order to allow HEM to manage the different residential loads with respect to time-of-use pricing.

\section{Data Availability}

There is no data taken from any source.

\section{Conflicts of Interest}

The authors have no conflicts of interest regarding this article.

\section{References}

[1] M. Lissere, T. Sauter, and J. Y. Hung, "Future energy systems: integrating renewable energy sources into the smart power 
grid through industrial electronics," IEEE Industrial Electronics Magazine, vol. 4, no. 1, pp. 18-37, 2010.

[2] C. Cecati, C. Citro, and P. Siano, "Combined operations of renewable energy systems and responsive demand in a smart grid," IEEE Transactions on Sustainable Energy, vol. 2, no. 4, p. 468476, 2011.

[3] Y. Guo, M. Pan, and Y. Fang, "Optimal power management of residential customers in the smart grid," IEEE Transactions on Parallel and Distributed Systems, vol. 23, no. 9, pp. 1593-1606, 2012.

[4] H. Wu, M. Shahidehpour, and A. Al-Abdulwahab, "Hourly demand response in day-ahead scheduling for managing the variability of renewable energy," IET Generation Transmission and Distribution, vol. 7, no. 3, pp. 226-234, 2013.

[5] Y. Guo, M. Pan, Y. Fang, and P. P. Khargonekar, "Decentralized coordination of energy utilization for residential households in the smart grid," IEEE Transactions on Smart Grid, vol. 4, no. 3, pp. 1341-1350, 2013.

[6] A. Papavasiliou and S. S. Oren, "Large-scale integration of deferrable demand and renewable energy sources," IEEE Transactions on Power Systems, vol. 29, no. 1, pp. 489-499, 2014.

[7] X. Liu, L. Ivanescu, R. Kang, and M. Maier, "Real-time household load priority scheduling algorithm based on prediction of renewable source availability," IEEE Transactions on Consumer Electronics, vol. 58, no. 2, pp. 318-326, 2012.

[8] S. Chen, N. B. Shroff, and P. Sinha, "Heterogeneous delay tolerant task scheduling and energy management in the smart grid with renewable energy," IEEE Journal on Selected Areas in Communications, vol. 31, no. 7, pp. 1258-1267, 2013.

[9] J. Byun, I. Hong, and S. Park, "Intelligent cloud home energy management system using household appliance prioritybased scheduling based on prediction of renewable energy capability," IEEE Transactions on Consumer Electronics, vol. 58, no. 4, p. 11941201, 2012.

[10] P. T. V. B. N. Kumar, S. Suryateja, G. Naveen, M. Singh, and P. Kumar, "Smart home energy management with integration of PV and storage facilities providing grid support," in 2013 IEEE Power \& Energy Society General Meeting, pp. 1-5, Vancouver, BC, Canada, July 2013.

[11] C.-S. Choi, J. I. Lee, and I.-W. Lee, "Complex home energy management system architecture and implementation for green home with Built-in Photovoltaic and motorized blinders," in 2012 International Conference on ICT Convergence (ICTC), pp. 295-296, Jeju, Korea (South), Oct 2012.

[12] M. Pipattanasomporn, M. Kuzlu, and S. Rahman, "An algorithm for intelligent home energy management and demand response analysis," IEEE Transactions on Smart Grid, vol. 3, no. 4, p. 21662173, 2012.

[13] M. Kuzlu, M. Pipattanasomporn, and S. Rahman, "Hardware demonstration of a home energy management system for demand response applications," IEEE Transactions on Smart Grid, vol. 3, no. 4, pp. 1704-1711, 2012.

[14] A. Q. H. Badar and A. Anvari-Moghaddam, "Smart home energy management system - a review," Advances in Building Energy Research, vol. 16, no. 1, pp. 1-26, 2020.
[15] L. Xu, R. Cheng, and J. Yang, "A new MPPT technique for fast and efficient tracking under fast varying solar irradiation and load resistance," International Journal of Photoenergy, vol. 2020, Article ID 6535372, 18 pages, 2020.

[16] O. Tremblay and L.-A. Dessaint, "Experimental validation of a battery dynamic model for EV applications," World Electric Vehicle Journal, vol. 3, 2009. 